\section{References}

1 Thomas CE. The ultrastructure of human amnion epithelium. J Ultrastruct Res 1975;13:65-84.

2 Franke H. Untersuchungen über die Ultrastruktur und Permeabilität des Amnions unter besonderer Berücksichtigung mikrofilamentärer und mikrotubulärer Strukturen. Arch Gynecol 1978;225:319-38.

3 Johansson SGO, Essler KJ, Sherman MS, Wahlström J, Bennich H. Alpha-fetoprotein (AFP) levels in maternal serum and amniotic fluid in singleton pregnant women in their 10th-25th week post last menstrual period. Acta Obstet Gynaecol Scand [Suppl] 1977;69:32.

${ }^{4}$ Huber J, Karlic H, Husslein P, Wagenbichler P. Bericht der 9. Jahrestagung der Österreichischen Biochemischen Gesellschaft. Salzburg: Universitätsverlag, 1982:27.

Correspondence and requests for reprints to $\mathrm{Dr}$ J Huber, I Universitäts-Frauenklinik, Spitalgasse 23, 1097 Wien, Austria.

\title{
A familial insertion involving an active nucleolar organiser within chromosome 12
}

\author{
J L WATT, D A COUZIN, D J LLOYD, G S STEPHEN, AND E MCKAY \\ Department of Genetics, University of Aberdeen, Foresterhill, Aberdeen AB9 $2 Z D$.
}

SUMMARY As far as the authors are aware this is the first report of the insertion of an active NOR into a non-acrocentric chromosome, although a simple translocation involving an active NOR has been previously recorded. More specifically, this case involves the non-reciprocal translocation of the centromere and stalk of an acrocentric into $12 \mathrm{p}$, generating an apparently stable dicentric chromosome. The insertion is seen in three generations and may be relatively genetically benign. The abnormality is fully described by $G$ and sequential $C$ banding, DA/DAPI fluorescence, kinetochore staining, and Ag-NOR staining, and the findings are discussed in the light of the limited published reports of insertion in man.

In man, simple translocations are fairly common two break rearrangements, as are pericentric and paracentric inversions. In total, two break rearrangements occur at a frequency of about 1 in 500 newborns. ${ }^{1}$ Insertions are normally considered to be three break events and are much rarer in man. In Drosophila, insertions can be artificially induced but are at least ten times less frequent than translocations. A similar situation is found in the mouse. ${ }^{2}$

Since the first unambiguous report of a human insertion, ${ }^{3}$ insertions have been reported either between ${ }^{4-13}$ or within ${ }^{1415}$ chromosomes. Therefore, with the exception of a few presumptive insertions reported in the pre-banding era, the authors are aware of only 13 documented cases in humans. The

Received for publication 14 October 1983. Accepted for publication 10 January 1984. rarity of such non-reciprocal rearrangements in man is further emphasised by the fact that the International Repository of Chromosome Anomalies ${ }^{16}$ lists details of only 17 insertions from a grand total of 12384 chromosome abnormalities, each of which is rare in its own right.

Although a non-acrocentric with an active NOR resulting from a simple, two break translocation has been previously reported, ${ }^{17}$ we describe here what we believe to be the first report of a three break rearrangement which involves the insertion of active nucleolar organiser material into $12 \mathrm{p}$. It has segregated uneventfully in three generations and therefore may be genetically benign.

\section{Case report}

A male infant was delivered to a 23 year old woman at 38 weeks' gestation after an uneventful pregnancy. The baby was heavy for dates weighing $4300 \mathrm{~g}$ and measured $55 \mathrm{~cm}$ from heel to crown with a head circumference of $35 \cdot 2 \mathrm{~cm}$. Physical examination revealed a baby with an asymmetrical face, slightly low set ears, a left simian crease, a short neck, widely spaced nipples, and a slight mongoloid slant to the eyes. A systolic murmur was noted at the left sternal edge and an echocardiogram suggested that this might be due to a small atrial septal defect. The baby's hospital stay was relatively uncomplicated and, despite being heavy for dates, he was not hypoglycaemic, but developed jaundice requiring phototherapy. In view of the chromosome analysis, clinical examination was repeated 3 weeks later. The baby had only mild mongoloid features, normal tone, and the cardiac murmur was no longer apparent. Developmental assessment at 9 months was normal. 


\section{Materials and methods}

Chromosome preparations were made from peripheral blood lymphocytes in the usual manner and subjected to a range of banding methods. $G$ banding was followed by $\mathrm{C}$ banding on the same cells so that the marker chromosome 12 could be identified before close scrutiny of the centromere region. DA/DAPI fluorescence, ${ }^{18}$ silver (Ag-NOR) staining, ${ }^{19}$ and a modification of Denton's kinetochore staining method ${ }^{20}$ completed the investigations.

\section{Results}

$G$ banding on the proband revealed a marker chromosome 12 with extra material in the short arm $(46, X Y, 12 p+)$ (fig 1a). Sequential $C$ banding showed that the marker chromosome was dicentric with the centromeres lying very close together, similar to some Robertsonian translocations (fig 1c). Ag staining depicted an active nucleolar organising region (NOR) (fig 1b), probably lying between the centromeres, together with four positive $G$ group chromosomes
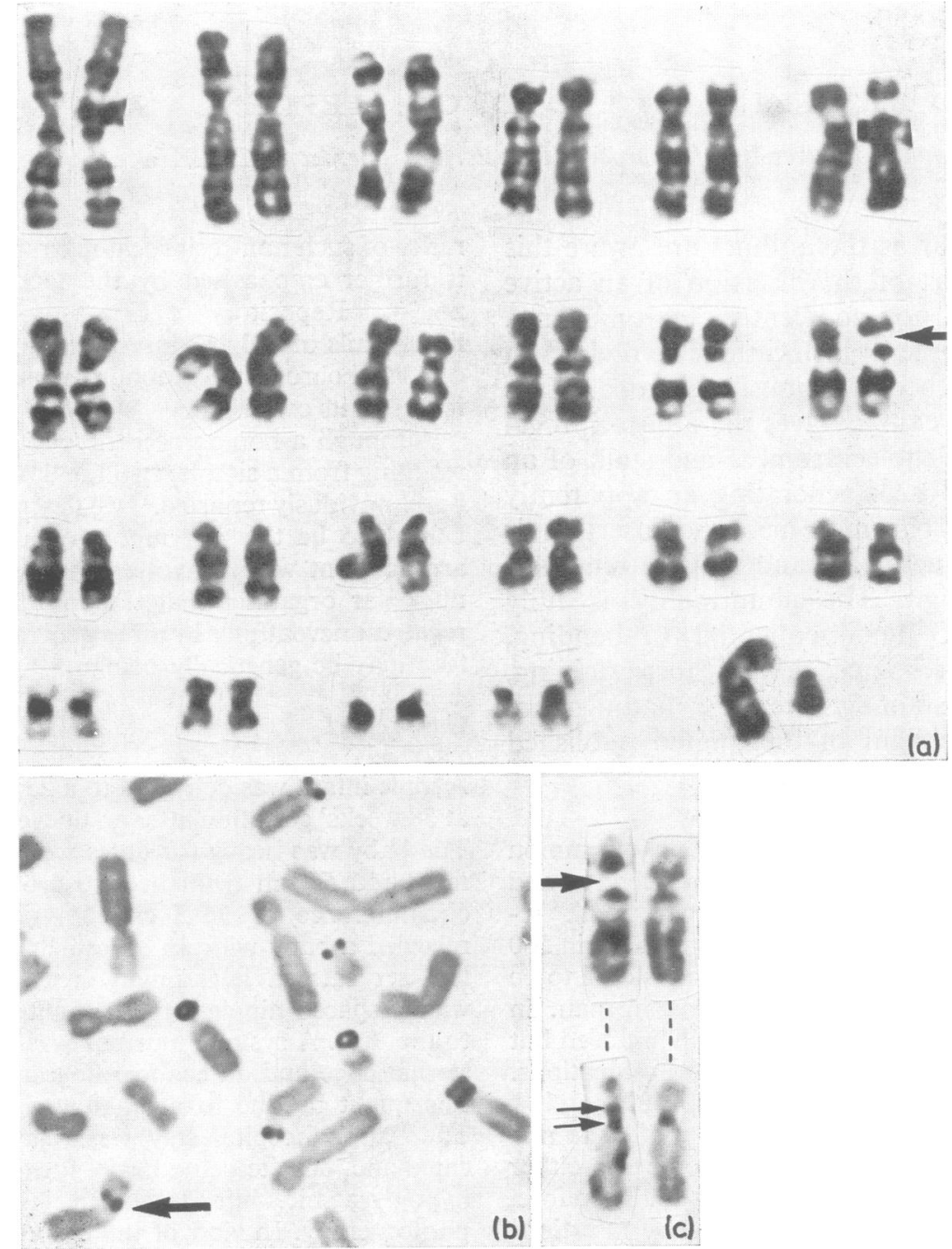

(a)

FIG 1 (a) $G$ banded karyotype of proband illustrating the marker $12 p+(46, X Y, 12 p+)$. (b) Partial metaphase (silver staining) showing active nucleolar organiser region $(N O R+v e)$ within $12 p$ (note that four $D$ group chromosomes and two $G$ group chromosomes are also NOR+ve). (c) Partial karyotype showing the pair of chromosomes 12 by $G$ banding (top) and sequential $C$ banding (bottom). The marker is shown to be dicentric. 


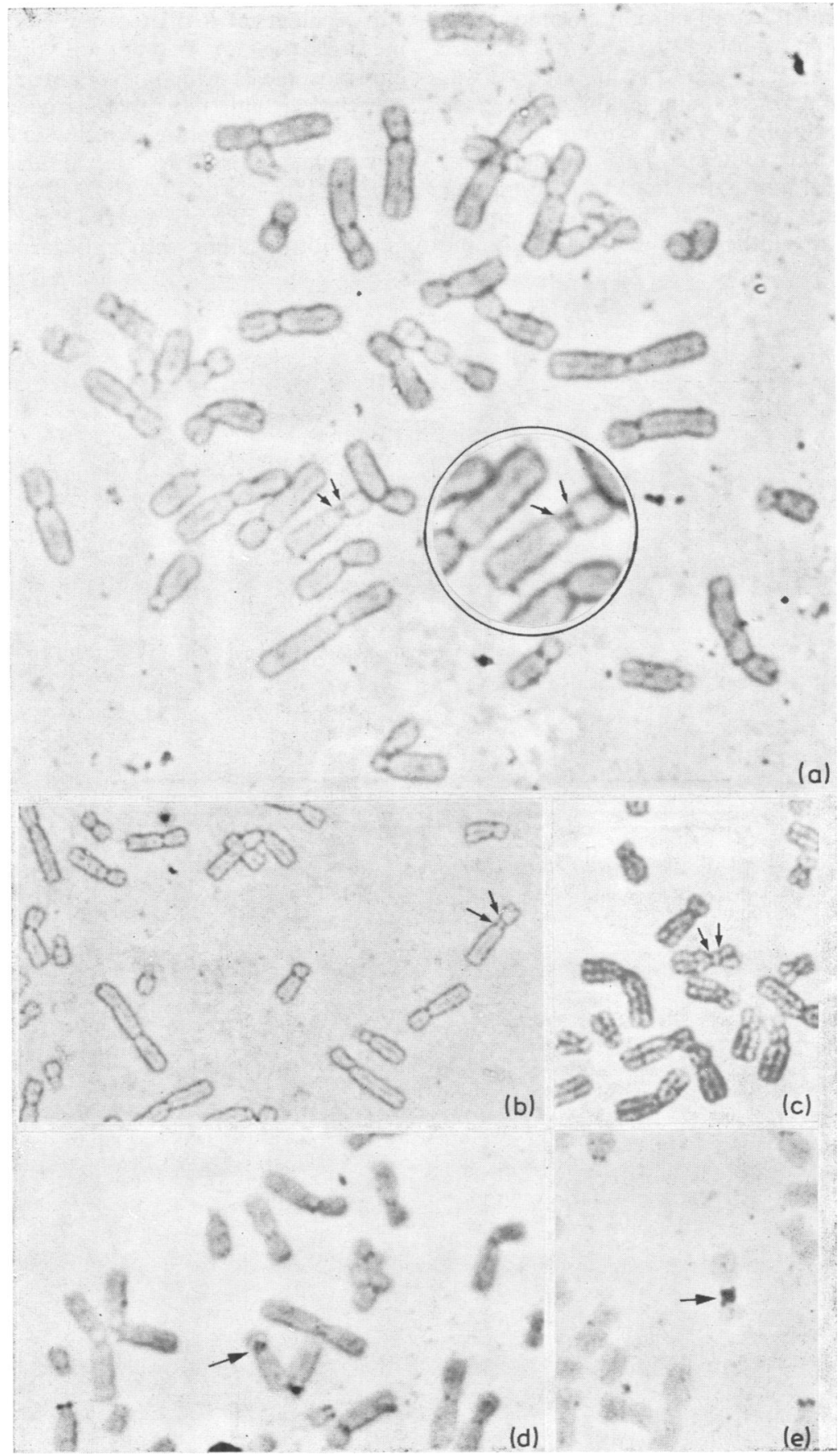

FIG 2 (a) Metaphase spread (kinetochore staining) verifying the dicentric nature of the marker. Note that NORs are - ve. (b-e) Partial metaphases (kinetochore staining) showing the range of appearance of the marker varying from a clear dicentric (in cells where only kinetochores are evident) to a mass of black staining material in cells where kinetochores + NORs are staining simultaneously. (The incidental staining of NORs in a small percentage of cells is typical of the kinetochore staining method used.) 
and five positive of the six $\mathrm{D}$ group chromosomes. Kinetechore staining verified the dicentric nature of the marker (fig 2). DA/DAPI fluorescence was negative for the marker, making it unlikely that the extra material originated from chromosome 15 . Parental samples were requested in order to attempt to determine the origin of the marker. The mother had an apparently normal $46, \mathrm{XX}$ female mitotic karyotype while the father was noted to have the
$12 p+$, identical to that of the child by all banding $\stackrel{\infty}{~}$ methods (fig 3c). In addition, the father had one $\stackrel{\oplus}{\rightarrow}$ chromosome 21 which never participated in satellite $\Rightarrow$ association with the other acrocentrics, lacked an $\stackrel{5}{?}$ active NOR, and showed a tiny $\mathrm{C}$ band, although a $\mathrm{O}$ functional centromere and $\mathrm{p}$ arms were present $(46, X Y, 12 p+, 21 p s-)$ (fig 3d). Grandparental $\frac{\bar{\omega}}{7}$ samples were obtained and the $12 p+$ was found in the $\stackrel{\mathbb{D}}{\Omega}$ grandmother along with two normal chromosomes
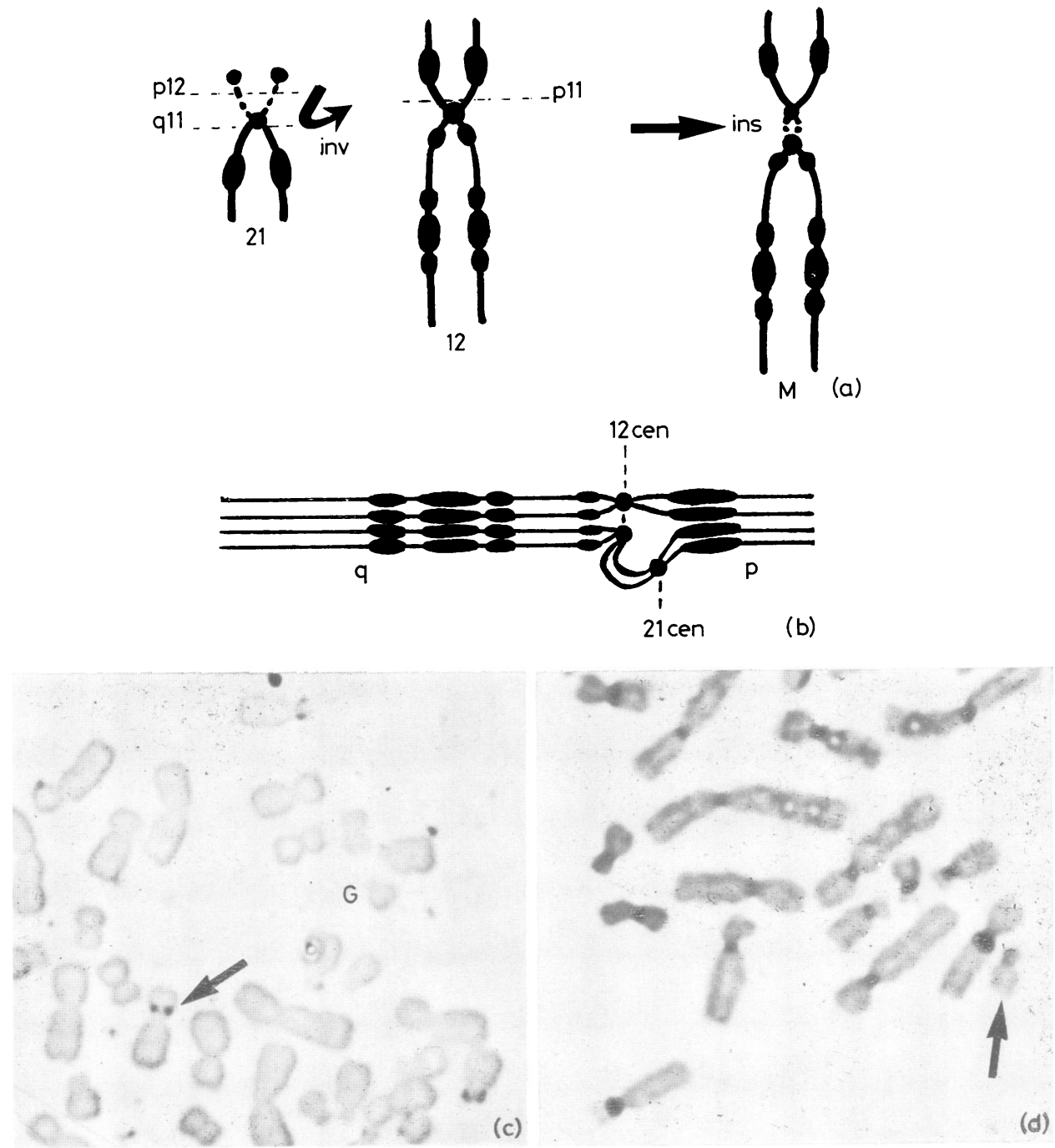

FIG 3 (a) Diagram of probable sequence of events to generate an inverted insertion. The three breakpoints involved, namely 21p12, 21q11, and 12p11, are indicated. (b) Unequal bivalent predicted to form at meiosis. The looped-out area would disappear in late pachytene (synaptic adjustment). (c) Partial metaphase (silver staining) from father showing $12 p+N O R+v e$, along with a $G$ group chromosome which is NOR-ve. $(d)$ Partial metaphase $(C$ banding) from father illustrating the negligible band of centromeric heterochromatin in one chromosome 21 , although a functional centromere and $p$ arms are clearly present. 
$21(46, X X, 12 p+)$, as in the proband. The grandfather had an apparently normal 46,XY karyotype including a variant 21 similar to that seen in the father.

\section{Discussion}

Since the child had mild mongoloid features the extra material was thought to be from chromosome 21. On the basis of this assumption and the child's karyotype, we could tell that the putative $21 \mathrm{p}$ arm and centromere were present in the marker, although it was not possible to determine how much of $21 \mathrm{q}$ may also be present, owing to the remarkable $\mathrm{G}$ band similarity of $21 \mathrm{q}$ and $12 \mathrm{p}$. Consideration of all the information to date indicates that we are dealing with a unique familial insertion of little more than the centromere and stalk region of an acrocentric (?21) into $12 \mathrm{p}$. We must assume that the satellite itself is absent since insertions are considered to be three break events and we can pinpoint only two breakpoints easily (12p11 and 21q11). We therefore require a second break on the participating acrocentric (?21p12) so that this insertion does not challenge the dogmatic integrity of the well accepted telomere hypothesis (fig 3a). The complementary acentric fragment which must have been generated along with the marker 12 has clearly been lost in a previous generation.

The significance of the mild clinical anomalies in the child is not clear, although, judging from the asymptomatic father and grandmother, we can perhaps postulate that developmental delay will be negligible. However, we cannot entirely rule out the possibility that the adults are balanced while the child is in some way unbalanced. It is interesting to note that the typical Down's phenotype is associated with trisomy for the distal long arm of $21 . .^{21}$ This fact, together with the father's karyotype $(46, \mathrm{XY}$, $12 \mathrm{p}+, 21 \mathrm{~s}-$ ), originally misled us by raising the possibility that he carried a two break balanced reciprocal translocation between 12 and 21 , while the child was therefore both trisomic for 21 and monosomic for $12 \mathrm{p}$. However, the fact that the child had no features of monosomy $12 p$ and only mild Down's-like abnormalities made this explanation unlikely, and analysis of the grandparental samples completely eliminated this possibility since it became clear that the 21 with the odd cytogenetic characteristics and the marker $12 p+$ were of quite separate origin and were segregating independently.

In at least two of the three generations then, this unique insertion can most conveniently be considered analogous to a rare polymorphism in that it is apparently genetically benign and segregating in true Mendelian fashion. The mildly abnormal phenotype in the child may be coincidental to the inversion, or may represent a small genetic effect attenuated by a different genetic background.

There is no evidence of reproductive problems in this family. This is perhaps not surprising since the rearrangement is unlikely to cause any distortions of meiotic segregation, since the interstitial inserted segment is small. The most likely pachytene configuration is a single unequal bivalent with a loopedout area which would tend to resolve itself late in pachytene when non-homologous pairing may occur. ${ }^{22}$ It would, therefore, be expected to segregate normally. Small insertions usually give rise to two unequal bivalents, ${ }^{10}$ with random segregation such that normal, balanced, and two types of unbalanced gametes result. Both types of abnormal subjects have been reported in certain human insertions. ${ }^{45}$ Generally speaking, cross overs in a multivalent containing an inverted insertion give rise to dicentrics and acentric fragments so that gametes would be inviable. This may be the reason for recurrent spontaneous abortion in some families. ${ }^{10}$ However, multivalent formation is extremely unlikely in the present case because of the size of the insertion and the fact that it is composed mainly of heterochromatin, centromere, and NOR material while meiotic pairing is brought about mainly by euchromatic recognition..$^{23}$ In the unlikely event of pairing with the chromosomes 21 , crossing over is improbable since centromere and heterochromatic regions of chromosomes rarely show chiasmata or evidence of the DNA nick-repair activities necessary for recombination, ${ }^{24}$ and the presence of an abnormal chromosome may predispose to unrelated nondisjunction $^{25}$ so that antenatal diagnosis is recommended for carriers of this unique chromosome rearrangement. The active NOR which has been seen to participate in satellite association may conceivably be an additional factor of unknown significance when attempting to predict the behaviour of the acrocentrics at meiosis. This may have special relevance since Robertsonian translocation is a common, spontaneously occurring anomaly thought to arise via ectopic crossing over between both homologous and non-homologous acrocentrics.

The authors would welcome comment on this family.

\section{References}

1 Jacobs PA, Melville M, Ratcliffe S, Keay AJ, Syme J. A cytogenetic survey of 11,680 newborn infants. Ann Hum Genet 1974;37:359-76.

2 Ohno S, Cattenach BM. Cytological study of an Xchromosome translocation in Mus musculus. Cytogenetics $1962 ; 1: 129-40$. 
${ }^{3}$ Gray JE, Syrett JE, Ritchie KM, Elliot WD. An interstitial translocation: chromosome No 1p to 4q. Lancet 1972;ii:92-3.

4 Therkelsen AJ, Hultén M, Jouessan J, Lundsten J, Christensen NC, Iversen T. Presumptive direct insertion within chromosome 2 in man. Ann Hum Genet 1973;36: 367-73.

5 Toomey KE, Mohandas T, Sparkes RS, Kabach MM, Rimoin DL. Segregation of an insertional chromosome rearrangement in 3 generations. $J$ Med Genet 1978;15: 382-7.

- Grace E, Sutherland GR, Bain AD. Familial insertional translocation. Lancet $1972 ;$ ii:231.

7 Rethoré MO, Lejeune J, Carpentier S. Trisomie pour la partie distale due bras court du chromosome $3 \mathrm{chez}$ trois germains. Premier example d'insertion chromosomique: ins (7;3)(q31 ;p21p26). Ann Genet (Paris) 1972;15:159-65.

8 Shapiro LR, Warburton D. Interstitial translocation in man. Lancet 1972;ii:712-3.

9 Berger R, Touati G, Derre J. "Cri du chat" syndrome with maternal insertional translocation. Clin Genet 1974; 5:428-32.

10 Chudley AE, Bauder F, Ray M, McAlpine PJ, Pena SDJ, Hamerton JL. Familial mental retardation in a family with an inherited chromosome rearrangement. J Med Genet 1974;11:353-63.

11 Fitzgerald MG. Complex five-break rearrangement. Clin Genet $1974 ; 5: 62-7$.

12 O'Donnell JJ, Hall BD, Conte FA, Romanowski JC, Epstein CJ. Down syndrome: localisation of locus to distal portion of long arm of chromosome 21. Pediatr Res 1975;9:315.

13 Sparkes RS, Salter WJ, Blaker RG, Muller HM. Insertional translocation into the $X$ chromosome of a 46,XY male. Clin Genet 1977;12:114-8.

14 Pan SG, Fatora SR, Sorg R, Garver KL, Steele MW. Meiotic consequences of an intrachromosomal insertion of chromosome No 1: a family pedigree. Clin Genet 1977; 12:303-13.

15 Grass FS, Schwartz RP, Deal JO, Parke JC Jr. Gonadal dysgenesis, ultra-X chromosome insertion, and possible position effect in an otherwise normal female. Clin Genet $1981 ; 20: 28-35$.
16 Borgaonker DS, Shaffer R, Reed WC, Jackson LG. Ф) Repository of chromosomal variants and anomalies in man. $\overrightarrow{\mathbb{D}}$ An international registry of abnormal karyotypes. Phila- $\because$ delphia: Thomas Jefferson University, 1981.

17 Varley JM, Gorden J, Hultén M. Familial reciprocal $\stackrel{\mathscr{S}}{\rightarrow}$ translocation $t(9 ; 13)(\mathrm{p} 11 ; \mathrm{p} 12)$ investigated by silver 0 staining and in situ hybridisation. Hum Genet 1981;59: $\frac{C}{\sigma}$ 422-8.

18 Spowart G. Reassessment of presumed $Y / 22$ and $Y / 15 \frac{\bar{S}}{\vec{D}}$ translocations in man using a new technique. Cytogenet $\stackrel{\unrhd}{\varrho}$ Cell Genet 1979;23:90-4.

19 Howell WM, Black DA. A rapid technique for producing ڤ silver-stained nucleolus organizer regions and trypsin- $\overrightarrow{0}$ giemsa bands on human chromosomes. Hum Genet 1978; 43:53-6.

20 Denton TE, Brooke WR, Howell WM. A technique for the simultaneous staining of both nucleolar organiser regions and kinetochores of human chromosomes with silver. Stain Technol 1977;52:311-3.

21 Williams JD, Summitt RL, Martens R, Kimbrell RA. N Familial Down syndrome due to $t(10 ; 21)$ translocation. ir Evidence that the Down phenotype is related to trisomy $w$ of a specific segment of chromosome 21. Am J Hum Genet $v$ $1975 ; 27: 478-85$.

22 Moses MJ. The synaptonemal complex and meiosis. In: Sparkes RS, ed. Molecular human cytogenetics. New York: Academic Press, 1977:101-25.

23 Miklos GL, Willcocks DA, Baverstock PR. Restriction $\frac{\bigcirc}{\sigma}$ endonuclease and molecular analysis of three rat genomes with special reference to chromosome rearrangement and $\mathbb{\complement}$ speciation problems. Chromosoma 1980;76:339-63.

24 Miklos GL, John B. Heterochromatin and satellite DNA in man: properties and prospects. Am J Hum Gene $\triangle$ $1979 ; 31: 264-80$.

25 Aurias A, Prieur M, Dutrillaux B. Systematic analys of 95 reciprocal translocations of autosomes. Hum Genef $1978 ; 45: 259-82$.

Correspondence and requests for reprints to $\mathrm{Dr} \stackrel{\mathrm{D}}{\mathrm{D}}$ Jessie L Watt, Department of Genetics, University $\overrightarrow{\vec{B}}$ of Aberdeen, Medical School Building, Foresterhill, Aberdeen AB9 2ZD.

\section{Partial trisomy 16 as a result of familial $16 ; 20$ translocation}

\section{E V DAVISON* AND J R BEESLEY †}

*Department of Human Genetics, 19 Claremont Place, Newcastle upon Tyne NE2 4AA; and †Department of Paediatrics, Newcastle General Hospital, Westgate Road, Newcastle upon Tyne NE4 6BE.

SUMMARY Although trisomy 16 is well recognised in spontaneous abortuses, ${ }^{1}$ it is infrequent in livebirths and there is little information about the clinical effects. ${ }^{3}$ We report two sibs with partial trisomy $16 \mathrm{q}$ resulting in infant death. Both children were severely growth retarded with small elfin faces, prominent foreheads, low set ears, abnormal external genitalia, and intractable diarrhoea.

Received for publication 17 November 1983. Accepted for publication 6 February 1984.

\section{Case reports}

The first child of healthy unrelated young parents $\%$ was born after an uncomplicated pregnancy by $N$ normal delivery at term. The child weighed $2125 \mathrm{~g}$ at $\underset{\omega}{\mathrm{\omega}}$ birth and her head circumference was $31.5 \mathrm{~cm}$. She $\sigma$ had distinctive facies, with a prominent forehead, $c$ small chin, and low set ears. She had bilateral fusion $\frac{\bar{D}}{\mathbb{D}}$ of the middle and fourth toes and very prominent $\stackrel{?}{?}$ labia majora. On the third day she developed watery 0 diarrhoea which necessitated intravenous fluid $\bar{O}$ therapy. Her condition improved briefly although 